\title{
El contexto de una carta: la conflictiva relación de dos filósofos católicos
}

\author{
Jorge ALONSO \\ Ciesas Occidente \\ jalonso@ciesasoccidente.edu.mx.
}

Resumen: En este artículo se ofrece un marco a la carta que el filósofo francés Gabriel Marcel mandó a Paulette Dieterlen en la que se manifiesta una ruptura con otro filósofo, Jacques Maritain. Se exploran los elementos afines entre Marcel y Maritain, se resumen sus aportaciones y se indagan sus diferencias. Por último, se proponen algunas pistas para tratar de explicar por qué, a pesar de que la muerte de la esposa de Maritain parecía haber sido una oportunidad de reconciliación, estos dos pensadores católicos terminaron distanciados.

Palabras clave: Marcel, Maritain, tomismo, existencialismo, ser

\begin{abstract}
This paper provides a context for the letter sent by the French philosopher Gabriel Marcel to Paulette Dieterlen, in which he expresses the disruption of his relation to his fellow philosopher Jacques Maritain. It also explores the common elements in Marcel's and Maritain's thought, summarizes their contributions and analyzes their differences. It concludes with some clues that might explain why these two Catholic thinkers remained estranged, even though the death of Maritain's wife could have provided an opportunity for their reconciliation.
\end{abstract}

Key words: Marcel, Maritain, tomism, existentialism, being

Paulette Dieterlen da a conocer una carta que había permanecido muchos años oculta, escrita por Gabriel Marcel, en la que se revela un profundo conflicto con Jacques Maritain. El presente escrito intenta dilucidar la relación entre estos dos filósofos católicos. ${ }^{1}$

${ }^{1}$ En la defensa de la tesis de doctorado de Julio Boltvinik, titulada Ampliar la mirada: un enfoque de la pobreza y el florecimiento humano, se suscitó una discusión entre la doctora Paulette Dieterlen y yo. Boltvinik planteaba que el florecimiento humano implicaba el desarrollo de las fuerzas esenciales humanas; inspirado en una obra de Fromm, destacaba que tener y ser eran dos modos de vivir (Fromm 1976). Sugerí que revisara a Gabriel Marcel, quien desde la década de 1930 había publicado una obra en la que argumentaba que el ser tenía que ver con la realidad más profunda, con la libertad creadora, lo cual lo distinguía de los predicados que uno pudiera tener. Marcel había detallado una fenomenología del tener destacando que el tener conllevaba una significación degradada del binomio tener-poseer (reivindicación exclusiva), y había hecho ver que el tener era algo independiente del sujeto, algo exterior, que podía perderse o destruirse. El tener también podía ser transmitido. Enfatizó que el tener implicaba la alienación de la persona frente 
Marcel y Maritain en el mismo campo

Jacques Maritain (1882-1973) recibió influencia de Henri Bergson y de Léon Bloy. Se casó con Raïssa Oumansoff en 1904. En 1906, el matrimonio, que vivió estrechamente unido, se convirtió al catolicismo. El filósofo Maritain llegó a ser un destacado exponente del tomismo y de la neoescolástica. ${ }^{2}$ Gabriel Marcel (1889-1973) también se vio influido por Bergson. Fue redactor, crítico, conferencista, escritor de obras de teatro y filósofo. De muy niño perdió a su madre. Su padre y su madrastra eran agnósticos. Sirvió en la Cruz Roja en la Primera Guerra Mundial y quedó impactado por ese desastre humano. En 1929, inspirado por François Mauriac, se convirtió al catolicismo. En 1947 perdió a su esposa, Jacqueline Boegner, cuyo amor fue fuente de profunda reflexión filosófica. Dedicó el libro Le Mystère de l'être (1951b) a su "bien amada siempre presente"; y el epígrafe de la introducción de su libro Présence et immortalité (1959) dice: "El mito de Orfeo y Eurídice está en el corazón mismo de mi existencia."”

Había muchas coincidencias entre ambos filósofos. Eran hombres de finales del siglo XIX cuyo pensamiento filosófico maduró en la primera mitad del siglo xx. Los dos estudiaron en la Sorbona, y habiéndose abierto al pensamiento de Bergson, se alejaron de sus líneas para adoptar cada uno su propio camino. Ambos se convirtieron al catolicismo y fueron importantes filósofos cristianos. Fueron marcados por sus matrimonios; el amor de sus respectivas esposas estuvo presente durante toda su vida. Sufrieron y rechazaron las dos grandes guerras; coincidie-

a las cosas. Avanzando en su reflexión, ubicó la frontera entre el tener y el ser en lo intransferible. Una persona no es lo que tiene, aunque el tener implicaba oscuramente una asimilación. De esta forma, el deseo era la opulencia del tener y la angustia del perder. La asimilación del tener al ser se hacía por medio del cuerpo, pues el sujeto podía cosificarse. No obstante, el éxito del ser estaba en que uno no era el conjunto de predicados; el ser trascendía todo tener. La distinción fueradentro, tan importante en el tener, no tenía sentido en el ser (Marcel 1935). Por su parte, Paulette Dieterlen no estaba tan convencida de que esa sugerencia embonara bien en una tesis inspirada en Marx, Giörgy Markus (1973) y Amartya Sen (1981), pues el sentido de la filosofía marceliana correspondía más bien a otra vertiente. Paulette Dieterlen no sólo conocía la obra de Marcel, sino que se había entrevistado con este filósofo.

${ }^{2}$ Sus principales obras están en la bibliografía. Tanto sus escritos como los de su esposa fueron publicados como obras completas en varios tomos, entre 1986 y 1990 en Friburgo.

${ }^{3}$ Los principales escritos de Marcel se encuentran en la bibliografía. La portada del libro Présence et immortalité tiene una réplica de un bajorrelieve del siglo v a.C. donde aparecen Orfeo y Eurídice.

Diánoia, vol. LII, no. 59 (noviembre 2007). 
ron en varios congresos de filosofía. Murieron el mismo año. Pero, por encima de todo, nació entre ellos una relación que tuvo tanto cercanías como desencuentros. ${ }^{4}$

Entre 1928 y 1939, Marcel y Maritain participaron en varios debates y se enviaban cartas. Maritain filosofaba con varios contemporáneos, entre los que destacaban Marcel, Jean Cocteau, Étienne Gilson y Mauriac. En 1930, en casa de Maritain se reunieron Emmanuel Mounier, Charles du Bos, Nikolai Berdiaev, Henri Ghéon, Marcel Arland, Jean Daniélou y Marcel para preparar un movimiento y una revista. El movimiento se llamó Tercera fuerza. En un principio se había previsto que la revista llevara el nombre de Univers, pero finalmente se prefirió Esprit. Del 16 al 31 de agosto de 1932, el grupo de intelectuales cristianos diseñó todo lo relativo al fondo y la forma de dicha revista. Se planteó como una publicación basada en investigación que debería servir a la búsqueda de nuevas soluciones para los problemas de entonces. En 1933, los jóvenes participantes en este esfuerzo editorial se proponían oponer el orden cristiano a la situación de crisis, sobre todo de valores. No hay que olvidar que ese año llegó al poder el nazismo. ${ }^{5}$ Marcel y Maritain contribuyeron en las páginas de Esprit con sus reflexiones filosóficas. A inicios de los años treinta, en casa de Marcel se organizaban reuniones semanales para discutir cuestiones filosóficas; algunas de ellas enfrentaban a Maritain y a Marcel. Raïssa, al recordar las conversaciones filosóficas de 1931 de Maritain con Mauriac, Gilson y Marcel, precisaba que, a pesar de que todos eran amigos, mantenían orientaciones contrarias. ${ }^{6}$

Al reseñar el escrito de Maritain sobre religión y cultura (donde éste destacaba que el cristianismo trascendía toda forma de cultura y política), Marcel fue muy laudatorio. ${ }^{7}$ Años más tarde, Mauriac, al defender a Maritain de los ataques que le hizo la prensa falangista, citó a Marcel, quien sostenía que un católico no podía ser obligado en cuanto católico

${ }^{4}$ Los datos biográficos de Gabriel Marcel están tomados de De Corte 1938; Sottiaux 1956; Davy 1959; Boutang 1977; Cain 1979; Prini 1984; Moran 1992; Bourgeois y Hanley 1997. Los datos biográficos de Jacques Maritain proceden de Bars 1959; Evans 1963; Dunway 1978; Daujat 1981; Doering 1983; Hubert y Floucat 1991; Barré 1996.

${ }^{5}$ Expresaban oposición a la tiranía del dinero y a la tiranía de las ideas. Las ideologías fascistas privaban a la persona del espacio de la libertad y la sometían a una estatolatría.

${ }^{6}$ Se puede consultar el tomo XV de sus obras completas.

${ }^{7}$ Esto se encuentra en un artículo de Gabriel Marcel titulado "Catholicisme et humanisme", que fue publicado por la revista L'Europe Nouvelle el 24 de enero de 1931. 
a tomar posición a favor de alguna de las partes en guerra. ${ }^{8}$ A causa de la Segunda Guerra Mundial, Maritain buscó refugio en Estados Unidos. Al terminar ese conflicto volvió a su patria, y entre 1945 y 1948 representó a Francia en El Vaticano.

Después de la guerra, Hannah Arendt tuvo relación tanto con Marcel como con Maritain, y fue invitada a una velada en casa del primero. Lo que más la impresionó fue la actitud humana de Marcel respecto de quienes tenían problemas económicos en el periodo posbélico. Tenía su bañera repleta de patatas y "cualquier asistente que declarara hallarse desprovisto de dinero y de comida, era invitado a cargar del tubérculo" (Young-Bruehl 2006, p. 207). Paul Tillich puso en contacto a Arendt con Maritain. El 22 de septiembre de 1945, Arendt publicó en Nation una reseña de un escrito (Adventures in Grace) de la esposa de Maritain, Raïssa, que tituló "Christianity and Revolution". Al abordar la revisión del pensamiento católico en Francia, se refirió a Maritain, en quien resaltaba la búsqueda de una certeza que lo sacara de las complejidades y confusiones de un mundo que no sabía siquiera de qué estaba hablando uno cuando ponía la verdad en su boca. Elisabeth Young-Bruehl, biógrafa de Arendt, destaca que ésta admiraba a Maritain; pero que le resultaba incómoda la necesidad que sentía Maritain de esa verdad entendida neotomistamente (Young-Bruehl 2006).

\section{Principales planteamientos de Maritain y Marcel, $y$ algunas divergencias}

Maritain abrazó el tomismo con gran entusiasmo y le dio un nuevo impulso. Recalcaba que en el presente había que irradiar la actualidad de lo eterno. Aceptando que la filosofía era subalterna de la teología, insistía en que consistía en el conocimiento de la realidad, en su inteligibilidad. Era posible una filosofía cristiana, la cual, además de recibir ayuda de Dios para filosofar, tenía que fincarse en la razón. El filósofo

${ }^{8}$ Mauriac, Georges Bernanos y Maritain habían quedado horrorizados por las atrocidades cometidas por los franquistas. Maritain criticaba la violencia tanto de los franquistas como de los republicanos. Diversos articulistas falangistas se admiraban de que renombrados escritores franceses no apoyaran la cruzada de Franco. Uno de ellos, Serrano Súñer, atacó por eso a Maritain. En 1938, Maritain, Marcel y Mauriac se sumaron a la firma de un llamamiento del Comité por la Paz Civil y Religiosa en España, en el que se protestaba contra los bombardeos aéreos masivos sobre centros de población civil. En él se recalcaba que si bastaban razones simplemente humanitarias para condenar tal masacre, ésta resultaba más repudiable cuando sus responsables proclamaban que estaban defendiendo la civilización cristiana (Lemuel 2005).

Diánoia, vol. LII, no. 59 (noviembre 2007). 
cristiano demostraba la existencia de Dios con argumentos racionales. Maritain explicaba que la fe orientaba a la filosofía como una estrella guía, pero que eso no hería su autonomía, pues juzgaba las cosas con leyes y principios propios. La razón se robustecía "por una especie de continuidad vital con luces superiores" (Maritain 1933, p. 54). Maritain eligió el tomismo porque satisfacía su exigencia de lo real, y sostuvo que el tomismo era el único medio para que la inteligencia pudiera vivir en la paz con Dios y conocer la verdad. Estaba convencido de que el tomismo era la guía de la verdad. Consideró que la filosofía, si era racional y verdadera, tenía que ser cristiana. Se ufanaba de ser tomista y tenía el convencimiento de que la inteligencia estaba hecha para el ser. Planteó que había dos funciones de la inteligencia: una especulativa y otra práctica. La primera tenía como finalidad el conocimiento, y la segunda, la acción orientada. Profundizó en la abstracción, en la que ubicó grados. En el primer grado, la inteligencia quedaba impregnada de la materia; en el segundo se hacía la abstracción de la materia sensible, y en el tercero se trataba del ser como tal. La razón era parte de la cultura, pero lo sobrenatural se encontraba por encima de la razón. Maritain veía en el mundo moderno una pérdida del sentido de la verdad y del ser. ${ }^{9}$

Maritain y Marcel chocaron por el tomismo del primero y el existencialismo del segundo. No obstante, hay que precisar que Marcel era enemigo de los "ismos" y repudiaba la esclavitud de los sistemas. Cuando Maritain publicó Degrés du savoir, Marcel fue especialmente crítico. Le escribió: "me parece que obras imprudentemente recurriendo siempre a un lenguaje escolástico, porque te arriesgas a dar la imagen de que la doctrina de la Iglesia está ligada a un lenguaje medieval". ${ }^{10}$

Mientras Maritain actualizaba la escolástica y construía un personalismo metafísico, Marcel impulsó el personalismo concreto, una filosofía como exploración interpersonal de su existencia, pues consideraba que la persona era un ser esencialmente expuesto, abierto a distintas realidades. Si bien Marcel se había iniciado dentro de las corrientes idealistas, pronto las había abandonado. Fue un acérrimo enemigo del positivismo y del empirismo, y un crítico del utilitarismo y del mundo sometido a la tecnocracia. Hacía ver que ningún sistema debía suplantar la vida. Se preocupaba por inquirir sobre las condiciones de posibilidad y sobre los límites de la eficacia. Marcel sostenía la primacía de lo concreto sobre lo abstracto; veía a la experiencia como maestra. Apuntaba que la conciencia era conciencia de y conciencia hacia. Defendió

\footnotetext{
${ }^{9}$ Se pueden encontrar estudios sobre el pensamiento de Maritain en Allard 1982; Posenti 1983, y Dougherty 2003.

${ }^{10}$ Esto se encuentra citado en Viotto 2004b.
} 
que el hombre era ser en situación, pero no meramente espacial. Había que ver al individuo concreto frente a una situación concreta; había que entender por medio de aproximaciones. Marcel mostró horror frente a la violencia colectiva. Criticaba al cristianismo de derechas porque comprometía el mensaje de Cristo; estaba en contra del clericalismo insolente. Aclaraba que la gente de derechas no era la única que tenía el monopolio del conformismo.

Existe un conformismo de izquierdas, existen poderosos de izquierdas, bienpensantes de izquierdas, tal como, antes de la última guerra, les decía yo a los embajadores, con gran escándalo de Jacques y Raïssa Maritain. Más aún, hay que añadir que ese conformismo de izquierdas ha de ser denunciado por lo menos tan despiadadamente como el otro [...] porque además entra en flagrante contradicción con los principios que pretende defender. (Marcel 1951a, p. 19)

Constataba Marcel que si había apatía, irían cayendo las libertades fundamentales. Incursionaba en la reflexión de cómo el hombre podía ser libre hic et nunc. Marcel pretendió devolver a la existencia la prioridad metafísica de la que el idealismo la había querido privar. Recalcó: "Hay algo que se llama vivir y algo que se llama existir: yo he escogido existir" (Marcel 1968a, p. 138). Indisolublemente unido a la condición de ser encarnado, el aspecto existencial se encuentra ligado a la condición de homo viator. La existencia es una situación centrada en un sujeto. En su filosofía concreta, Marcel explicaba que lo que se saludaba como existente, al mismo tiempo se le reconocía como que un día no existiría más. Así, la casa donde él había vivido ya no existía mientras filosofaba, porque había sido demolida. Ese no existir no afectaba las cosas sino en la medida en que eran objetivables; pero, por paradójico que pareciera, el solo hecho de poder evocar su casa al mismo tiempo que se decía que no existía suponía en cierto sentido que todavía era, pues unida a su realidad, permanecía. No se trataba sólo de una imagen conservada, sino que emergía en el plano ontológico de la conciencia. Esto era más fuerte cuando se trataba de un ser humano. Marcel precisaba que la existencia no era una modalidad del ser. Depende del sujeto el que su existencia sea (o no sea) transmutada en ser. En esta reflexión, Marcel se distanciaba tanto del empirismo como del racionalismo. Pedía que se partiera de la admiración (Troisfontaines 1968, t. I, pp. 187-220).

Marcel profundizó en la distinción entre problema y misterio. Mientras que el problema implica arrojarse en los datos sobre los que hay que trabajar, el misterio es eminentemente metaproblemático. Marcel

Diánoia, vol. LII, no. 59 (noviembre 2007). 
encontró una íntima conexión entre la reflexión y el misterio. El pensamiento metafísico de Marcel fue siempre sobre el misterio y no sobre el problema (lo que está fuera, enfrente de mí). El misterio es aquello en que el hombre se encuentra comprometido; y para reconocer el misterio se necesita un recogimiento. Cuando el hombre pregunta por lo que $e s$, se encuentra tan implicado que no puede problematizarse. No se autoexplica sino como metido dentro del misterio, que es sentido no de incognoscible, sino de íntimo, de participación del ser. Por el recogimiento se llega al ser, a captarse siendo. Ante una primera reflexión que se realiza con abstracciones sobre los objetos (de la que procede la ciencia y la tecnología), propugnó una segunda reflexión que va a lo profundo humano.

Ante las experiencias de las guerras (las dos guerras mundiales y la guerra fría), Marcel estaba convencido de que las masas eran lo humano degradado; que en sí mismas no eran educables, pues la única educable es la persona. En cambio, las masas son fanatizables por la propaganda. Marcel se pronunció en contra de las técnicas del envilecimiento usadas por el poder. El envilecimiento consiste en poner al individuo sin contacto consigo mismo, lo que hace manipulable su conciencia. Las técnicas de envilecimiento son ese conjunto de procedimientos llevados a cabo deliberadamente para atacar y destruir en el individuo el respeto que de sí mismo pueda tener. Resulta fundamental señalar cuándo a lo vil se lo convierte institucionalmente en elite con voluntad de humillar. El poder condena a soportar la mediocridad. Por la propaganda se realiza la manipulación de la opinión. Hay comunicaciones que se presentan como seducciones. La mentira juega a favor de la servidumbre. Se han envilecido las mismas bases de la discusión. Los medios de comunicación ejercen un papel corruptor. Se tiene que mantener un núcleo contra todas las intromisiones del poder.

Marcel defendió que lo humano debía controlar los medios técnicos. Fue enemigo de todos los fanatismos, y llamaba la atención acerca de fanatismos larvados. Contempló al mundo fatigado, en desamparo. Pero contra el fatalismo propuso la esperanza.

Fue un impulsor de un existencialismo no individualista que tenía en cuenta la comunidad. Insistió en que el hombre no puede reducirse a lo que tiene, a un objeto, ni a su haber, ni a sus cualidades, ni a su historia, ni a su pura actualidad. Al reentrar en sí, el hombre sale de sí porque se experimenta con los otros. El hombre es en comunión. Ese recogimiento no aísla, sino que hace trascender. En esta dinámica, Marcel reflexionó sobre la fidelidad creadora. Ante el compromiso que pedía fidelidad, muchos argüían que eso llevaba a algo ilegítimo, porque sin 
ser yo dueño de mi posterior estado, o no lo cumpliré o tendré que obrar contra mi actual estado. Frente a esto, Marcel argumentaba que había promesas que comprometían lo íntimo del ser. Ser fiel es crearse. Además de la comunicación intersubjetiva, Marcel planteó la unión con el ser trascendente. La fidelidad no inhibe, sino que desarrolla la disponibilidad, destroza el egoísmo. El encuentro del tú y del yo se realiza en una comunión del plano del misterio, inexplicable por causas mensurables anteriores, inobjetivable, inverificable. En el plano de la existencia, todo está constituido por sus relaciones. El yo no emerge sino en tensión con otro. Marcel plantea que el hombre no accede al ser si no obra libremente en la intersubjetividad con otra persona que no cosifica. El acto por el cual el yo se pone implica siempre la referencia a otro. El lazo espiritual entre dos personas produce una presencia. Se pasa de un él al tú, y se llega al nosotros. El yo no es solo, sino que es con los tú. Sobreviene la necesidad de una invocación mutua con disponibilidad y compromiso. Uno se da. Dar es obrar en ser a la vista de otro ser, de persona a persona (Troisfontaines 1968, t. II, pp. 9-60).

Tanto la muerte de su madre como la de su esposa lo condujeron a pensar la muerte del ser querido. Hay una fórmula materialista ante la muerte del ser querido: "lo perdí", que lleva una idea de objetivización; la subjetivista, que lo quiere suplir con objetos; y la intersubjetiva, siendo con, que lo mantiene en el ser, y lo hace presente. No es un deseo del orden del tener, sino del ser; ser nosotros, ser con. Si yo reniego de ese lazo, reniego de algo de mi ser. Marcel insiste en el importante papel de la esperanza que es "yo espero en ti para nosotros".

Marcel profundizó en el misterio familiar. Si el hijo acepta su situación como una vocación de ser, si se acepta, se recrea en el reconocimiento, reconoce la situación y la agradece. En ese reconocimiento libre supera el plano del tener y llega al del ser en un nosotros. Si bien la base del matrimonio es el contrato, su ser es el compromiso libre y fiel. No acepta que el acto constitutivo de la familia sea algo meramente biológico. El matrimonio toma su sentido cuando surge la misteriosa necesidad de ser nosotros delante del tercer tú que ha de venir. La paternidad sólo se entiende en el plano del misterio. No se reduce a la procreación. Implica también el reconocimiento. Marcel va más allá. La familia no es la única experiencia existencial de la comunidad. Hay que llegar a la caridad encarnada y universal, a la fraternidad humana. ${ }^{11}$

${ }^{11}$ Una revisión de la obra de Marcel se puede encontrar en los dos tomos publicados por Roger Troisfontaines en 1968. Su pensamiento ha sido estudiado, entre otros, por Ricœur 1948; Gallagher 1963; Keene 1967; Applebaum 1986, y Urabayen 2001.

Diánoia, vol. LII, no. 59 (noviembre 2007). 
Marcel recalca que uno va por el camino haciéndose. Es una filosofía concreta del pensamiento pensante, por lo que Marcel fue calificado de filósofo itinerante (Davy 1959). Su método no es orgánico, sino un diario de lo concreto. Sus planteamientos no pueden desvincularse de su proceso de reflexión. Se lo ha visto como un filósofo especialmente huidizo, cuya metodología es de lo inverificable (Prini 1963).

Maritain calificó la filosofía de Marcel de metafísica no genuina, como un sustituto (Maritain 1948). Ante la afirmación marceliana de que podía tenerse experiencia, pero no conocimiento de Dios, Maritain defendía los argumentos filosóficos que probaban la existencia de Dios; y recalcando que todo discurso filosófico dependía de la intuición del ser, criticaba a Marcel que usara la palabra meditación y rechazara la de intuición. ${ }^{12}$ Por su parte, Marcel le hizo a Maritain una fuerte acusación:

Cuando Jacques Maritain afirmaba que, hablando con rigor, se podía ser católico — pero no inteligente- sin ser tomista, emitía una afirmación propia de un fanático, puro y simple; y se podía mostrar mediante qué transiciones casi imperceptibles es siempre posible pasar de ese fanatismo venial hasta el fanatismo sin más. (Marcel 1951a, p. 114)

No obstante, la relación humana era más fuerte que las divergencias filosóficas. Cuando Raïssa Maritain cayó víctima de la enfermedad que la llevaría a la tumba, Marcel le escribió a Jacques: "Considero muy importante que sepan que estoy con ustedes, y que les pido perdón si de algún modo los he entristecido involuntariamente." Jacques le respondió: "Es verdad que ciertas cosas escritas por ti le han hecho mucho mal a Raïssa, pero estoy seguro que ella te perdona. En cuanto a mí, no tengo nada que perdonarte, valgo menos que nada."13 Un mes después murió Raïssa. Éste fue un golpe muy duro para Maritain, quien optó por irse a Toulouse a vivir en 1961 con los Hermanitos de Jesús, y en 1970 tomó los hábitos en esa congregación identificada y dedicada a los pobres.

\section{Pistas para entender su distanciamiento}

¿Qué sucedió entre Maritain y Marcel después de la muerte de Raïssa? Lo que tenemos ahora es la carta que le mandó a Paulette Dieterlen por la que sabemos que un año antes de la muerte de ambos no había

${ }^{12}$ Se puede consultar el tomo V de las obras completas del matrimonio Maritain.

${ }^{13}$ Cartas del 4 y 6 de octubre de 1960, transcritas en Viotto 2004a. 
relación entre ellos. Evidentemente, la relación se había enfriado. Algo similar había sucedido entre el mexicano Efraín González Luna, que era el ideólogo católico del Partido Acción Nacional, y Maritain.

González Luna fue a Estados Unidos a participar en el Congreso Interamericano de Problemas Sociales organizado por la National Catholic Welfare Conference a principios de los años 1940. Maritain y González Luna fueron los encargados de redactar las conclusiones de ese Congreso, lo cual propició una cercanía ideológica y humana entre ambos. Sin embargo, años después, González Luna publicó un artículo en el que criticó algunas posiciones de Maritain. González Luna había advertido, en un texto de Maritain sobre el fin del maquiavelismo, algo que calificó de ese patético titubeo en el que frecuentemente tropezaban escritos influidos por la catástrofe de la Segunda Guerra. Maritain decía que cuando se consideraba el curso de las guerras desatadas por el maquiavelismo total, había que preguntarse hasta qué punto los agresores, que no respetaban nada, obligaban al resto de la humanidad a recurrir a la terrible ley de las justas represalias o a prescindir momentáneamente de ciertas reglas jurídicas. González Luna comentaba que la pregunta no debía permanecer sin respuesta. Apuntaba que era un signo terrible de la oscuridad de esos momentos el hecho de que precisamente alguien como Maritain llegara a formular tal pregunta. Y recalcaba que la inhibición, así fuera temporal, de la norma jurídica era una de las brechas más peligrosas en la defensa de la ciudad del espíritu. Aceptar eso implicaba abrir sin restricciones las puertas a la violencia y al crimen. $\mathrm{Y}$ añadió que para combatir a los agresores no resultaba necesario tal recurso. La justicia no era un poder desarmado. Precisamente la elaboración de un eficaz sistema de prevenciones y sanciones en contra de los transgresores de la norma era, y en esos momentos más que nunca, una tarea indeclinable de los servidores del espíritu (González Luna 1943). Hubo otro punto en el que González Luna externó su divergencia respecto de otra postura de Maritain. No compartía la tesis de que el hombre en cuanto individuo estaba sujeto a la sociedad y al Estado, pero que en cuanto persona era libre de reglas y de los vínculos de lo social y lo político (Calderón Vega 1951). Esas críticas implicaron una ruptura. Cuando, en el segundo semestre de 1954, el chihuahuense Carlos Ochoa le pidió a González Luna que hiciera una carta de presentación de su cuñada, la escritora Emma Godoy, para que Maritain le pudiera dar una cita en París, González Luna respondió que Maritain no estaba en Francia, pues era profesor en Princeton. Pero, además de la información, le brotó del corazón una aclaración: "lo que pareció ser un comienzo de una verdadera amistad acabó en un 
brusco y deliberado silencio por su parte, tal vez a consecuencia de sus inclinaciones y criterios en materia política". ${ }^{14}$ Ésa es una pista de lo que pudo haber sucedido entre Maritain y Marcel.

La enfermedad de Raïssa y su muerte debieron de haber sacudido a Marcel, quien había puesto en boca de uno de sus personajes de teatro la afirmación de que amar a un ser era decir "tú no morirás". Marcel era consecuente con su pensamiento y mantenía una disposición de permeabilidad a los sucesos y de disponibilidad. Eso implicaba superar el carácter cerrado del tiempo y de la muerte. Veía las relaciones humanas no como relaciones de posesión, sino de aceptación y creatividad. Pensaba que nada estaba perdido para un hombre que servía a un gran amor o vivía la amistad; y que todo estaba perdido para el que estaba solo, pues no había mayor sufrimiento que estar solo. En esas circunstancias, Marcel ha de haber revivido la muerte de su esposa.

Émile M. Cioran, ${ }^{15}$ en un texto escrito en la primavera de 1985, resalta algunos rasgos importantes para entender a Marcel. El filósofo Marcel hubiera querido ser un compositor dedicado por completo a la música. Sus actividades favoritas eran escribir y escuchar música. Leía mucho, le gustaba el teatro. Tenía una naturaleza ascética que era el secreto de su vitalidad. Rara vez se quejaba o lamentaba. Tenía un nerviosismo explosivo. Cioran lo califica de alegre y bueno. Nunca se detenía cuando lo que se necesitaba era una buena obra, pues actuaba rápidamente sin sacar provecho. Tenía el don de la comunicación. Siempre estaba interesado. Su curiosidad lo mantenía abierto al mundo; poseía una mente abierta, ansiosa de entender otro punto de vista o incluso la opinión de un contrario. Estaba listo para enfrentar a un adversario, pues disfrutaba el desafío. Para él, la contradicción era el pan de cada día; la necesitaba para trabajar. Adaptaba su temperamento y juicio a la espontánea e impredecible discusión. Respetaba los pensamientos de las personas con las que conversaba; y mantenía la fe en la gente y en los lugares. No enseñaba la filosofía en las aulas, sino que la practicaba en el parque y en la casa. Invitaba a jóvenes a su casa y conversaba con ellos sobre cualquier tema. Quería conocer la mente de las personas con las que hablaba. Había meditado mucho sobre la muerte para trascenderla. Tenía una desmesurada necesidad de amar y ser amado (Cioran 1985). Teniendo en cuenta estos rasgos, podría entenderse que la

${ }^{14}$ Carta de González Luna a J. Carlos Ochoa, 10 de septiembre de 1954, Archivo Efraín González Luna; el subrayado es mío.

${ }^{15} \mathrm{El}$ intelectual rumano Cioran (1911-1995), sin sentirse perteneciente a alguna nación, vivió la mayor parte de su vida en Francia. Fue un amigo de Marcel y lo acompañaba al teatro y a viajes. 
separación entre Maritain y él estuvo más bien marcada por el primero. La carta que le mandó a Paulette Dieterlen muestra que había distancia; y la petición de que no se diera a conocer era porque no quería que el pequeño lazo que tal vez quedaba se rompiera definitivamente. Había el rescoldo de una amistad conflictuada por la divergencia.

\section{BIBLIOGRAFÍA}

Allard, J.L., 1982, Education for Freedom, University of Notre Dame Press, Notre Dame.

Applebaum, D., 1986, Contact and Alienation. The Anatomy of Gabriel Marcel's Metaphysical Method, University Press of America, Washington.

Barré, J.L., 1996, Jacques et Raïssa Maritain. Les mendiants du ciel, Stock, París. Bars, H., 1959, Maritain en notre temps, Bernard Grasset, París.

Bourgeois, P. y K.R. Hanley, 1997, "Gabriel Marcel”, en C.E. Winquist, V.E. Taylor (comps.), Routledge Encyclopedia of Postmodernism, Routledge, Londres.

Boutang, P., 1977, Gabriel Marcel interrogé par Pierre Boutang, La Place, París.

Calderón Vega, L., 1951, “iAlegatos contra 'pragmáticos'?”, La Nación, no. 531, 17 de diciembre.

Cain, S., 1979, Gabriel Marcel, Hillary House, Nueva York.

Cioran, É.M., 1985, "Gabriel Marcel: apuntes para un relato", disponible en: $<$ http://www.hemerodigital.unam.mx/ANUIES/itam/estudio/estudio02/ sec_51.html >.

Daujat, J., 1981, Jacques Maritain, trad. Rafael Tomás Caldera, Dimensiones, Caracas.

Davy, M.M., 1959, Un Philosophe itinérant, Gabriel Marcel, Flammarion, París.

De Corte, M., 1938, Gabriel Marcel, Téqui, París.

Doering, B., 1983, Jacques Maritain and the French Catholic Intellectuals, University of Notre Dame Press, Notre Dame.

Dougherty, J.P., 2003, Jacques Maritain: An Intelectuel Profile, Catholic University of America Press, Washington.

Dunway, J.M., 1978, Jacques Maritain, Twayne, Boston.

Evans, J.W., 1963, Jacques Maritain: The Man and his Achievement, Sheed and Ward, Nueva York.

Fromm, E., 1976, To Have or to Be?, Harper and Row, Nueva York.

Gallagher, K.T., 1963, The Philosophy of Gabriel Marcel, Fordham University Press, Nueva York.

González Luna, E., 1943, “Titubeo”, La Nación, no. 67, 23 de enero.

Hubert, B. e Y. Floucat (comps.), 1991, Jacques Maritain et ses contemporains, Desclée de Brower, París.

Keene, S., 1967, Gabriel Marcel, John Knox Press, Richmond.

Lemuel, J., 2005, "Guerra civil y escritores extranjeros", disponible en: <http://www.nodo50.org/arerevolucionaria/masarticulos/mayo2005/ guerrayescritores2.htm $>$.

Diánoia, vol. LII, no. 59 (noviembre 2007). 
Marcel, G., 1968a, Journal métaphysique (1928-1933), Aubier, París.

— 1968 b, Pour une Sagesse tragique, Plon, París.

— 1967, Essai de philosophie concrète, Gallimard, París.

— 1964, La Dignité humaine, Aubier, París.

—_, 1959, Présence et immortalité, Flammarion, París.

_ _ 1951a, Les Hommes contre l'humain, La Colombe, París.

—_, 1951b, Le Mystère de l'être, I y II, Aubier, París.

$\ldots$, 1945, Homo viator, Aubier, París.

—_, 1940, Du Refus à l'invocation Gallimard, París.

_ 1935 , Etre et avoir, Aubier, París.

—_, 1927, Journal métaphysique (1914-1923), Gallimard, París.

Maritain, J., 1986-1990, OEuvres complètes, Éditions Universitaires, Friburgo.

—_, 1966, Le Paysan de la Garonne, Desclée de Brower, París.

— 1948, Son OEuvre philosophique, Bibliotèque de la Revue Thomiste, París.

— 1 1936, Humanisme intégral, Aubier, París.

—_, 1933, De la Philosophie chrétienne, Desclée de Brower, París.

__, 1932, Degrés du savoir, Desclée de Brower, París.

— 1927, Primauté du spirituel, Plon, París.

Markus, G., 1973, Marxismo y “antropología”, trad. Manuel Sacristán, Grijalbo, Barcelona.

Moran, D., 1992, Gabriel Marcel: Existentialist Philosopher, Dramatist, Educator, University Press of America, Lanham.

Posenti, V., 1983, Jacques Maritain: Oggi, Vita e Pensiero, Milán.

Prini, P., 1984, Gabriel Marcel, Economica, París.

—, 1963, Gabriel Marcel y la metodología de lo inverificable, Luis Miracle, Barcelona.

Ricœur, P., 1948, Gabriel Marcel et Karl Jaspers, Temps Présent, París.

Sen, A., 1981, Poverty and Famines. An Essay on Entitlement and Deprivation, Clarendon Press, Oxford.

Sottiaux, E., 1956, Gabriel Marcel: philosophe et dramaturgue, Nauwelaerts, París.

Troisfontaines, R., 1968, De l'Existence à l'être, Nauwelaerts, París, 2 tomos.

Urabayen, J., 2001, El pensamiento antropológico de Gabriel Marcel: un canto al ser humano, EUNSA, Pamplona.

Viotto, P., 2004a, "Los Maritain y la filosofía contemporánea", Información Filosófica, vol. 1, no. 2, pp. 222-250.

_ 2 2004b, "Maritain y los existencialistas cristianos", disponible en: <http://www.humanismointegral.com/DOCS_1_Maritain/140_19_Exist. Cristianos.html>.

Young-Bruehl, E., 2006, Hannah Arendt. Una biografía, trad. Manuel Llopis Valdés y Gonzalo Torné de la Guardia, Paidós, Barcelona.

Recibido el 31 de enero de 2007; aceptado el 22 de marzo de 2007. 